\title{
Basal E2, FSH, and AFC of Endometrioma Patients Undergoing In Vitro Fertilization (IVF)
}

\author{
Rendy Primananda Zilmi ${ }^{\mathrm{a}}$, Jimmy Yanuar Annas ${ }^{\mathrm{b} *}$, Muhammad Yohanes Ardianta \\ Widyanugraha $^{\mathrm{b}}$, Relly Yanuari Primariawan ${ }^{\mathrm{b}}$, Lila Dewata Azinar $^{\mathrm{b}}$ \\ ${ }^{a}$ Obstetric and Gynecology Resident, Faculty of Medicine, Universitas Airlangga, Surabaya 60115, Indonesia \\ ${ }^{b}$ Department of Obstetrics and Gynecology, Faculty of Medicine, Universitas Airlangga, Surabaya 60115, Indonesia \\ *Corresponding author: jimmyyanuar@fk.unair.ac.id
}

\begin{abstract}
Background: Endometriosis is a common disease among women of reproductive age and often associated with infertility. Endometrioma is one of the most common manifestations in endometriosis patient. In Vitro Fertilization is one of the methods used as infertility management in endometriosis women. There are some basal parameters that could affect the IVF result, such as basal E2, FSH and AFC. This study aim is to analyze the basal E2, FSH and AFC of women with endometrioma patients compared to non-endometriosis patients.

Methods: This is an analytical observational study with case-control method using medical record data at the Fertility Polyclinic of Graha Amerta Dr. Soetomo General Hospital Surabaya, Indonesia in period of 20182020.

Result: There was a significant difference in basal E2 levels, the group of women with endometrioma had lower basal E2 levels than non-endometriosis (mean $22.52 \pm 10.58$ vs $31.49 \pm 11.41 ; \mathrm{p}=0.001$ ). There were no significant differences in basal E2, FSH and AFC in post endometrioma cystectomy group compared to endometrioma with conservative treatment.
\end{abstract}

Conclusion: Endometrioma patients had lower basal E2 level compared to non-endometriosis patient. Consideration of endometrioma cystectomy prior to IVF should be done wisely.

Keywords: Endometriosis, Endometrioma, In Vitro Fertilization, Infertility

\section{INTRODUCTION}

Endometriosis is a common disease among women of reproductive age with a prevalence of $6-10 \%$ and is often associated with infertility. As many as 35-50\% of endometriosis patients experience infertility and 25$50 \%$ of infertile women experience endometriosis ${ }^{(1,2,3)}$. Endometrioma is one of the most common manifestations in endometriosis cases, about $17-44 \%$ of patients with endometriosis have endometrioma manifestations $^{(4,5)}$. In Vitro Fertilization (IVF) is one of the Assisted Reproductive Technology (ART) methods that are used as infertility management in endometriosis women.

There are several basal parameters that can affect the level of fertility and the success of ovarian stimulation during ovum pick up (OPU) in IVF method, including estradiol (E2), Follicle Stimulating Hormone (FSH), Anti-Mullerian Hormone (AMH), and Antral Follicle Count (AFC) ${ }^{(6,7)}$. Women with endometriomas experience disturbances in these basal parameters, resulting in impaired folliculogenesis and oocyte function and decreased ovarian reserve which can affect the ovarian response during stimulation ${ }^{(8,9,10)}$.

Cystectomy surgery is one of the treatments for endometriomas that still controversial. Several studies have shown that this procedure can decrease ovarian reserve, which can lead to disturbances in the basal parameter such as Estradiol, FSH and $\mathrm{AFC}^{(11,12)}$, while other studies showed no significant changes in those parameters 
after surgery ${ }^{(13,14)}$. This study was conducted to analyze the ovarian stimulation response of women with endometriomas compared to non-endometriosis women in the IVF method, so it can be an aspect of consideration in determining management in patients with endometriomas and infertility.

\section{METHOD}

This study is an analytic observational study with a case control method to analyze the basal E2, FSH and AFC in women with endometriomas compared to non-endometriosis women using medical record data at Fertility Polyclinic of Graha Amerta Dr. Soetomo General Hospital Surabaya for the period of 2018-2020. The inclusion criteria for the case group in this study were the medical records of women diagnosed with endometriosis with endometrioma manifestations at the Fertility Polyclinic of Graha Amerta Dr. Soetomo General Hospital Surabaya and had regular menstrual cycles, while the control group was the medical records of women diagnosed with one benign gynecologic abnormality at the Fertility Polyclinic of Graha Amerta Dr. Soetomo General Hospital Surabaya and had regular menstrual cycles. Exclusion criteria were incomplete medical record data, PCOS, and hyperprolactinemia.

The case group (endometrioma women) later devided into post endometrioma cystectomy and conservative treatment. The post endometrioma cystectomy group was the medical record of women with cystectomy history that diagnosed endometrioma from histologic examination result. The endometrioma conservative treatment was the medical record of women underwent IVF with endometrioma diagnosis from laparoscopic or transvaginal sonography examination.

The basal E2, FSH and number of AFC data was collected on day 3 of menstrual cycle before the ovarian stimulation start. Statistical analysis was performed using SPSS ver. 26.0. Measurement values for the descriptive data were compared using a t-test and the results expressed as mean \pm standard deviation with significance set at $\mathrm{p}<0.05$.

\section{RESULT}

During the period of 2018-2020, there were 518 total infertility cases undergoing IVF, 40 of them $(7.5 \%)$ with a diagnosis of endometriosis. From a total of 40 cases with endometriosis, 34 cases (85\%) found with endometrioma manifestation (16 cases of endometrioma with conservative treatment and 18 cases of postcystectomy endometrioma). 34 cases were taken consecutively (16 cases with unexplained infertility, 15 cases with tubal factor disorders, and 3 cases with uterine factor disorders) with the same age range for the control group (non-endometriosis group).

Table 1. Comparison of endometrioma and non-endometrioma group

\begin{tabular}{|l|l|l|l|}
\hline Variable & $\begin{array}{l}\text { Endometrioma } \\
(\mathbf{n = 3 4})\end{array}$ & $\begin{array}{l}\text { Non-endometriosis } \\
(\mathbf{n = 3 4})\end{array}$ & $\mathbf{p}$ Value \\
\hline Age (y.o) & $31.37 \pm 3.77$ & $32.09 \pm 3.82$ & 0.434 \\
\hline Infertile duration (years) & $5.99 \pm 3.84$ & $7.11 \pm 3.61$ & 0.210 \\
\hline Basal E2 (pg/mL) & $22.52 \pm 10.58$ & $31.49 \pm 11.41$ & 0.001 \\
\hline FSH (IU/L) & $5.23 \pm 3.24$ & $6.04 \pm 1.94$ & 0.206 \\
\hline AFC & $7.63 \pm 3.34$ & $8.6 \pm 2.57$ & 0.177 \\
\hline
\end{tabular}


Table 1 shows no significant difference in age and infertile duration between both groups. There was a significant difference in basal E2 levels, where the group of women with endometriomas had lower basal E2 levels than non-endometriosis (mean $22.52 \pm 10.58$ vs $31.49 \pm 11.41 ; \mathrm{p}=0.001$ ), but there was no significant difference on FSH (5.23 \pm 3.24 vs 6.04 $\pm 1.94 ; \mathrm{p}=0.206)$ and AFC (7.63 \pm 3.34 vs $8.6 \pm 2.57$; $\mathrm{p}=0.177)$ parameter.

Comparison of post endometrioma cystectomy and non-endometriosis group (Table 2) showed similar result as table 1. There was a significant difference in basal E2 levels $(21.70 \pm 9.59$ vs $31.49 \pm 11.41 ; \mathrm{p}=0.002)$ and there was no significant difference on FSH $(5.05 \pm 3.28$ vs $6.04 \pm 1.94 ; p=0.269)$ and AFC $(7.42 \pm 3.29$ vs $6.6 \pm 2.57$; $\mathrm{p}=0.151)$.

Table 2. Comparison of post endometrioma cystectomy and non-endometriosis group

\begin{tabular}{|l|l|l|l|}
\hline Variable & $\begin{array}{l}\text { Post endometrioma } \\
\text { cystectomy } \\
(\mathbf{n}=\mathbf{1 9})\end{array}$ & $\begin{array}{l}\text { Non-endometriosis } \\
(\mathbf{n}=\mathbf{3 5})\end{array}$ & p Value \\
\hline Age (y.o) & $31.11 \pm 3.84$ & $32.11 \pm 3.82$ & 0.372 \\
\hline Infertile duration (years) & $5.68 \pm 4.01$ & $7.11 \pm 3.61$ & 0.187 \\
\hline Basal E2 (pg/mL) & $21.70 \pm 9.59$ & $31.49 \pm 11.41$ & 0.002 \\
\hline FSH (IU/L) & $5.05 \pm 3.28$ & $6.04 \pm 1.94$ & 0.169 \\
\hline AFC & $7.42 \pm 3.29$ & $6.6 \pm 2.57$ & 0.151 \\
\hline
\end{tabular}

The statistical test results in Table 3 do not show significant differences in each variable. This shows that post endometriomas cystectomy did not provide a significant difference compared to the endometrioma conservative treatment group.

Table 3. Comparison based on endometrioma management

\begin{tabular}{|l|l|l|l|}
\hline Variable & $\begin{array}{l}\text { Post endometrioma } \\
\text { cystectomy } \\
(\mathbf{n}=\mathbf{1 9})\end{array}$ & $\begin{array}{l}\text { Endometrioma } \\
\text { conservative } \\
\text { management } \\
(\mathbf{n = 1 5})\end{array}$ & p Value \\
\hline Age (y.o) & $31.11 \pm 3.84$ & $31.69 \pm 3.79$ & 0.656 \\
\hline Infertile duration (years) & $5.68 \pm 4.01$ & $6.34 \pm 3.73$ & 0.620 \\
\hline Basal E2 (pg/mL) & $21.70 \pm 9.59$ & $23.49 \pm 11.90$ & 0.626 \\
\hline FSH (IU/L) & $5.05 \pm 3.28$ & $5.43 \pm 3.29$ & 0.736 \\
\hline AFC & $7.42 \pm 3.29$ & $7.88 \pm 3.48$ & 0.695 \\
\hline
\end{tabular}

\section{Discussion}

\section{Characteristic of patients}

During 2018-2020 period, 34 cases of endometrioma were found undergoing IVF program at the Fertility Polyclinic of Graha Amerta Dr Soetomo General Hospital, and 34 cases of IVF patients without endometriosis were consecutively selected with the same age range as the control group. The sample characteristic in this research was similar from age and infertile duration characteristic. The infertility duration is related to the number of oocytes and the success rate of IVF. The longer infertile duration, the lower number of oocytes 
retrieved and the lower of IVF success rate ${ }^{(15,16)}$.

2. Basal parameters

Comparison of group with endometrioma and non-endometriosis (Table 1) and group of post endometrioma cystectomy and non-endometriosis (Table 2) showed a significant difference only in basal E2 levels. This could be due to the occurrence of apoptosis in granulosa cells which caused low E2 serum levels in the endometrioma group and in the post cystectomy group. The use of GnRH agonist in cases of endometrioma and post endometrioma cystectomy can also lead to lower basal E2 levels in the endometrioma and post endometrioma cystectomy group when compared to non-endometriosis group ${ }^{(17,18,19)}$. The comparison between the post endometrioma cystectomy and conservative endometrioma groups (Table 3) did not provide a statistically significant difference. The use of GnRH agonist in the two groups may be the cause of the no difference in basal E2 and FSH levels.

Endometrioma patients had chronic inflammatory processes or cystectomy procedures that can cause a decrease in ovarian reserve with low AMH and AFC values ${ }^{(20,21)}$. In this study, we did not compare AMH levels because the incomplete AMH data, either because of not included in the medical record or were not examined due to cost constraints for patients. The average number of AFC in the endometrioma group in this study had a lower tendency than non-endometriosis group (7.63 \pm 3.34 vs $8.6 \pm 2.57$ ), although not statistically proven $(\mathrm{p}=0.117)$. Comparison of the number of AFC in the post endometrioma cystectomy group and nonendometriosis also gave a significant difference in this study $(\mathrm{p}=0.151)$. This is in accordance with previous studies which stated that surgical procedures for cystectomy did not provide a significant difference in the number of AFC compared to the endometriosis group ${ }^{(13)}$.

3. Cystectomy management in endometrioma

Data above showed that cystectomy in endometriomas did not provide significant differences in basal parameters (E2, FSH and AFC). This shows that cystectomy in cases of endometrioma and infertility should be performed only if there are indications such as possible difficulties during OPU due to an endometrioma mass or accompanied by severe pain that interferes patient activities. Inadequate cystectomy procedures can potentially cause damage to healthy ovarian tissue and a decrease in ovarian reserve which can lead to infertility problems and a decrease in the percentage of successful ART program ${ }^{(18,22)}$

\section{Conclusion}

The endometrioma group had lower basal E2 levels compared to non-endometriosis group. Consideration of endometrioma cystectomy prior to IVF should be done wisely. Further research is needed to determine factors that influence the IVF success in endometriosis women.

\section{Ethical Approval}

The research was approved by the Human Research Ethics Committee, Dr. Soetomo General Teaching Hospital, with approval number 0550/LOE/301.4.2/VIII/2021.

\section{Conflicts of Interest}

The authors declare that there are no conflicts of interest.

\section{Referrences}

1. Miller JE, Ahn SH, Monsanto SP, Khalaj K, Koti M, Tayade C. Implications of immune dysfunction on endometriosis associated infertility. Oncotarget. 2017;8(4):7138-7147. doi:10.18632/oncotarget.12577

2. Broi MG Da, Ferriani RA, Navarro PA. Ethiopathogenic mechanisms of endometriosis-related infertility. JBRA Assist Reprod. 2019;23(3):273. doi:10.5935/1518-0557.20190029

3. Gordts S, Koninckx P, Brosens I. Pathogenesis of deep endometriosis. Fertil Steril. 2017;108(6):872-885.e1. doi:10.1016/j.fertnstert.2017.08.036 
Gałczyński K, Jóźwik M, Lewkowicz D, Semczuk-Sikora A, Semczuk A. Ovarian endometrioma - A possible finding in adolescent girls and young women: A mini-review. J Ovarian Res. 2019;12(1). doi:10.1186/s13048-019-0582-5

5. Ozgur K, Bulut H, Berkkanoglu M, Coetzee K, Ay S. Oocyte maturation-index as measure of oocyte cohort quality; A retrospective analysis of 3135 ICSI cycles. Middle East Fertil Soc J. 2015;20(1):37-42. doi:10.1016/j.mefs.2014.04.005

6. Kasapoglu I, Ata B, Uyaniklar O, Seyhan A, Orhan A, Yildiz Oguz S, et al . Endometrioma-related reduction in ovarian reserve (ERROR): a prospective longitudinal study. Fertil Steril. 2018;110(1):122-127. doi:10.1016/j.fertnstert.2018.03.015

7. Alborzi S, Keramati P, Younesi M, Samsami A, Dadras N. The impact of laparoscopic cystectomy on ovarian reserve in patients with unilateral and bilateral endometriomas. Fertil Steril. 2014;101(2):427-434. doi:10.1016/j.fertnstert.2013.10.019

8. Nicolaus K, Bräuer D, Sczesny R, Jimenez-Cruz J, Bühler K, Hoppe I, et al. Endometriosis reduces ovarian response in controlled ovarian hyperstimulation independent of AMH, AFC, and women's age measured by follicular output rate (FORT) and number of oocytes retrieved. Arch Gynecol Obstet. 2019;300(6):1759-1765. doi:10.1007/s00404-019-05337-z

9. $\quad$ Elder K, Dale B. In-Vitro Fertilization. Published online December 31, 2019. doi:10.1017/9781108611633

10. Chiang HJ, Lin PY, Huang FJ, Kung FT, Lin YJ, Sung PH, et al. The impact of previous ovarian surgery on ovarian reserve in patients with endometriosis. BMC Womens Health. 2015;15(1). doi:10.1186/s12905-015-0230-1

11. Litta P, D’Agostino G, Conte L, Saccardi C, Cela V, Angioni S, et al. Anti-Müllerian hormone trend after laparoscopic surgery in women with ovarian endometrioma. Gynecol Endocrinol. 2013;29(5):452-454. doi:10.3109/09513590.2012.758704

12. Obino MER, Papini F, Vergine F, Micelli E, Malacarne E, Sergiampietri C, et al. Endometriosis-related infertility: does surgery improve IVF outcomes? A single-center observational retrospective analysis. - Gynecological and Reproductive Endocrinology and Metabolism 2021, 2(1), pp. 46-53

13. Hendarto H. The Role of Advanced Age and Duration of Infertility on Oocyte Number Retrieved during In Vitro Fertilization. J NERS. 2014;9(2):183. doi:10.20473/jn.v9i22014.183-186

14. Wolff MV, Schwartz AK, Bitterlich N, Stute P, Fäh M. Only women's age and the duration of infertility are the prognostic factors for the success rate of natural cycle IVF. Arch Gynecol Obstet. 2019;299(3):883-889. doi:10.1007/s00404-018-5034-8

15. Stilley JAW, Birt JA, Sharpe-Timms KL. Cellular and molecular basis for endometriosis-associated infertility. Cell Tissue Res. 2012;349(3):849-862. doi:10.1007/s00441-011-1309-0

16. Dunselman GAJ, Vermeulen N, Becker C, Calhaz-Jorge C, D'Hooghe T, De Bie B, et al. ESHRE guideline: Management of women with endometriosis. Hum Reprod. 2014;29(3):400-412. doi:10.1093/humrep/det457

17. Tian Z, Zhang Y, Zhang C, Wang Y, Zhu HL. Antral follicle count is reduced in the presence of endometriosis: a systematic review and meta-analysis. Reprod Biomed Online. 2021;42(1):237-247. doi:10.1016/j.rbmo.2020.09.014

18. Lima ML, Martins WP, Coelho Neto MA, Nastri CO, Ferriani RA, Navarro PA. Assessment of ovarian reserve by antral follicle count in ovaries with endometrioma. Ultrasound Obstet Gynecol. 2015;46(2):239-242. doi:10.1002/uog.14763

19. Romanski PA, Brady PC, Farland L V., Thomas AM, Hornstein MD. The effect of endometriosis on the antimüllerian hormone level in the infertile population. J Assist Reprod Genet. 2019;36(6):1179-1184. doi:10.1007/s10815-019-01450-9

20. Dong X, Liao X, Wang R, Zhang H. The impact of endometriosis on IVF/ICSI outcomes. Int J Clin Exp Pathol. 2013;6(9):19111918. Accessed September 23, 2021./pmc/articles/PMC3759500/

21. Sur D, Chakravorty R, Athwal A, Javed A. Effect of the endometriomas on ovarian stimulation and pregnancy rate on assisted reproductive outcomes. Fertil Sci Res. 2018;5(2):55. doi:10.4103/fsr.fsr_19_18

22. Hamdan M, Omar SZ, Dunselman G, Cheong Y. Influence of endometriosis on assisted reproductive technology outcomes: A systematic review and meta-analysis. Obstet Gynecol. 2015;125(1):79-88. doi:10.1097/AOG.0000000000000592 